\title{
Evaluation of microbial inhibition properties of green and chemically synthesized ZnO nanoparticles
}

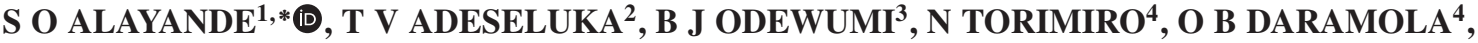

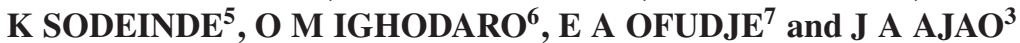 \\ ${ }^{1}$ Department of Industrial Chemistry, First Technical University, P.M.B. 5015, Ibadan, Nigeria \\ ${ }^{2}$ Department of Physics, Bingham University, P.M.B. 005, Karu, Nigeria \\ ${ }^{3}$ Centre for Energy Research and Development, Obafemi Awolowo University, P.M.B. 021, Ile Ife, Nigeria \\ ${ }^{4}$ Department of Microbiology, Obafemi Awolowo University, P.M.B. 13, Ile Ife, Nigeria \\ ${ }^{5}$ Department of Chemistry, Federal University, P.M.B. 373, Oye-Ekiti, Nigeria \\ ${ }^{6}$ Department of Biochemistry, Lead City University, Ibadan, Nigeria \\ ${ }^{7}$ Department of Chemical Sciences, Mountain Top University, Prayer City, Nigeria \\ *Author for correspondence (gbengaalayande@gmail.com; samson.alayande@tech-u.edu.ng)
}

MS received 25 April 2018; accepted 7 September 2018; published online 27 March 2019

\begin{abstract}
Nanosized particles of zinc oxide have gained much attention due to several applications which includes bacterial inhibition. Therefore, this work evaluates zinc oxide properties synthesized using reduction (chemical) and bioreduction (green) processes and their corresponding inhibition potentials. The bio-reduction process was achieved using Amaranthus spinosus at $70^{\circ} \mathrm{C}$ while the reduction process was initiated in the chemical process using sodium hydroxide. The optical measurement of $\mathrm{ZnO}$ was carried out using an UV-Vis spectrophotometer. The structural and morphological properties of the synthesized $\mathrm{ZnO}$ were evaluated using Fourier transform infrared spectroscopy, X-ray diffractometry and scanning electron microscopy. The elemental composition was carried out using energy dispersive X-ray spectroscopy. The antimicrobial activity property of the nanoparticles was tested against Pseudomonas aeruginosa, Salmonella typhi and Shigella dysenteriae. The degree of susceptibility of $\mathrm{ZnO}$ nanoparticles was higher in the bio-reduction process than chemically synthesized for selected microorganisms. A sustainable pathway for development of bio-antibiotic is presented.
\end{abstract}

Keywords. ZnO nanoparticles; Spiny amaranth; antimicrobial activity; microbial inhibition.

\section{Introduction}

Metal oxide nanoparticles have various functions that are not observed in the bulk phase [1-3] and have been studied extensively because of their exclusive catalytic, optical, electronic, magnetic, antimicrobial $[1,4,5]$ wound healing and anti-inflammatory properties [6]. Among the metal oxide nanoparticles, zinc oxide $(\mathrm{ZnO})$ is interesting because it has vast applications in various areas because of optical, piezoelectric and magnetic properties, bacterial inhibition and gas sensing. It has a direct wide band gap energy of about $3.2 \mathrm{eV}$ at room temperature and it is thermally and chemically stable and also a versatile material with good electrical and optical properties. It has optical transparency in the visible range. It is a non-toxic and a strong antibacterial agent. Many studies have been conducted on the antibacterial properties of $\mathrm{ZnO}$ nanoparticles [7-11]. $\mathrm{ZnO}$ nanoparticles have bactericidal effects on both gram-positive and gram-negative bacteria $[7,12]$. They also have antibacterial activity against spores that are resistant to high temperature and high pressure. The antimicrobial agents are natural or synthetic compounds which are helpful in the inhibition of microbial growth.
$\mathrm{ZnO}$ nanoparticles are environmentally friendly and easy to synthesize [13]. Many methods are being used to synthesize $\mathrm{ZnO}$ nanoparticles which include: chemical synthesis methods like the sol-gel process, precipitation, spray pyrolysis, laser ablation, electrochemical deposition, combustion, chemical vapour deposition, micro emulsion, hydrothermal; the green method and the physical method which is often called top-down approach, and includes methods such as diffusion, irradiation, thermal decomposition, arc discharge etc., and this method often requires special equipment or operational control [14-17]. The chemical method consumes less power and can be carried out in a robust atmosphere during the synthesis but leads to the presence of some toxic chemicals adsorbed on the surface that may have adverse effects in medical applications $[7,18]$. Green synthesized $\mathrm{ZnO}$ nanoparticles are clean and free of harsh chemicals that make them suitable for biological, pharmaceutical and medical applications [19] which give the method an advantage over traditional synthesis.

The techniques known as green methods of synthesis, are based on the use of moderately pollutant-free chemicals for production of nanomaterials, promote use of benign solvents 
such as water and natural extracts while pollution is reduced at source. It is enhanced to prevent waste than to treat or clean up waste after it is formed. The use of plants towards synthesis of nanoparticles has numerous advantages compared to only microbes; this includes the presence of broad variability of bio-molecules in plants which can act as capping or reducing agents and thus increases the processes of reduction and stabilization of nanoparticles. Also, the use of microorganisms for nanoparticles synthesis involves elaborate process of maintaining intracellular synthesis, cell culture and multiple purification steps. Plant-mediated biological synthesis (green synthesis) of nanoparticles is currently gaining importance due to its simplicity, non-toxic reducing agents, eco-friendliness and extensive antimicrobial activity $[7,18]$. The use of plant extract or plant biomass could be an alternative to chemical and physical methods for the synthesis of zinc nanoparticles [7,18]. The plant phytochemical with antioxidant properties is accountable for the preparation of metal and metal oxide nanoparticles. These phytochemicals including polyols, terpenoids, flavonoids, carbohydrates, saponins, alkaloid and protein are responsible for the synthesis of several nanoparticles $[1,7,18]$.

The plant Spiny amaranth (Amaranthus spinosus), sometimes called spiny pigweed is a troublesome weed of vegetables, row crops and pastures in warm climates that is widely distributed in the humid zone of the tropics [20-23]. This plant adapts itself to various kinds of environments, grows rapidly, resists drought, heat and pests and produces large amounts of biomass [21-23]. Extracts of the leaf have been used curatively for diarrhoea, dysentery, excessive menstrual flow, ulcers and intestinal haemorrhaging. The leaves are used for several medicinal purposes which include: treatment of intestinal bleeding, excessive menstruation and diarrhoea [20-23]. It is well established that some plants contain compounds able to inhibit microbial growth [20-23]. This study is therefore aimed to evaluate the antimicrobial inhibition properties of $\mathrm{ZnO}$ nanoparticles synthesized by a green method using $S$. amaranth extracts and a chemical method. A contributory role of antimicrobial properties of plant extract is another merit to promote green chemistry. To the best of our knowledge, there is no report on comparison of efficacy of green and chemically synthesized nanoparticles for antimicrobial inhibition.

\section{Experimental}

\subsection{Materials}

Zinc nitrate (99\% purity) and sodium hydroxide (pellet, 99\%) were used as the introductory material and was supplied by Sigma-Aldrich Chemicals. This was used without further purification. Distilled and deionized water was used in all experimental work. A fresh leaf of $S$. amaranth (figure $1 \mathrm{~A}$ shows a typical $S$. amaranth leaf) was washed thoroughly with distilled water, ground and was filtered through filter paper.
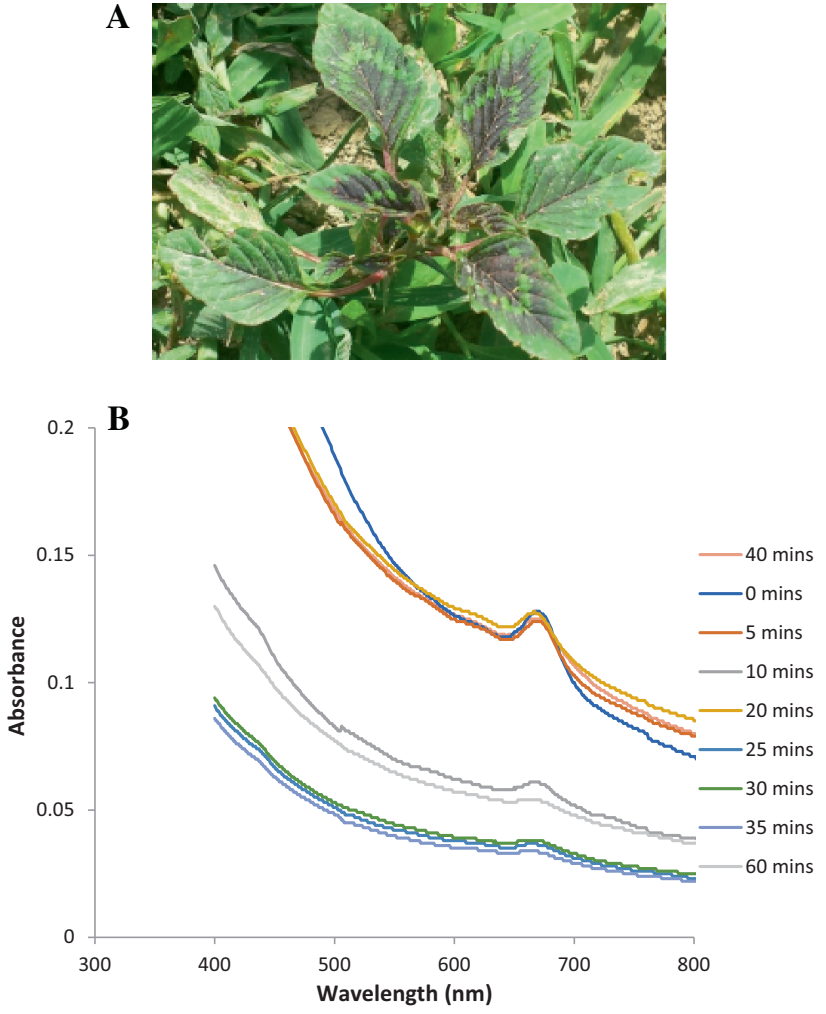

Figure 1. (A) S. amaranth leaf and (B) UV-Vis spectra of $\mathrm{ZnO}$ nanoparticles using $S$. amaranth leaf extract.

\subsection{Test organisms}

The test organisms used for antimicrobial sensitivity testing included Pseudomonas aeruginosa, Salmonella typhi and Shigella dysenteriae. The organisms were sourced from the Department of Microbiology Obafemi Awolowo University, Nigeria.

\subsection{Collection and preparation of plant leaf extract (S. amaranth)}

S. amaranth leaves were collected from an open field in Igboya, Ile-Ife, Nigeria. The leaves were washed several times with distilled water to remove dust particles and were collected using sieve. The leaves were finely cut and homogenized using mortar and pestle. Extraction was carried out in the ratio of 1:5 wt/v using distilled-deionized water. The mixture was filtered with Whatman no. 1 filter paper and the filtrate was collected and kept at $4^{\circ} \mathrm{C}$ before centrifuging at $1200 \mathrm{rpm}$ for $5 \mathrm{~min}$ to remove biomaterials. The extract was used as a reducing agent and was kept for phytochemical screening (table 1) of plant extract and for further experiments.

\subsection{The phytochemical screening of the plant extracts}

The phytochemical screening of the plant extracts was carried out using the standard procedure [25]. Qualitative analysis of 
Table 1. Phytochemical constituent of S. amaranth aqueous leaf extracts.

\begin{tabular}{|c|c|}
\hline Proteins & + \\
\hline Carbohydrates & + \\
\hline Phenols & + \\
\hline Tannins & + \\
\hline Flavonoids & + \\
\hline Saponins & + \\
\hline Glycosides & + \\
\hline Steroids & + \\
\hline Terpenoids & + \\
\hline Alkaloids & + \\
\hline
\end{tabular}

+ Represents the presence of the phytoconstituent; - represents the absence of the phytoconstituent.

the selected phytochemicals was achieved using standard procedure [25]. Test for alkaloids: plant extract was evaporated to dryness, while residue was then heated in a water bath with $2 \%$ (v/v) $\mathrm{HCl}$ acid. The mixture was treated with Mayer's reagent after cooling and filtration. Yellow precipitate was observed which confirmed the presence of alkaloids. Saponins: Plant was extracted with methanol extract and boiled for a few minutes. About $2.5 \mathrm{ml}$ of the extract was added to $10 \mathrm{ml}$ of the distilled water in a test tube and on shaking well for about $30 \mathrm{~s}$ frothing was observed. Flavonoids: $1.5 \mathrm{ml}$ of $50 \%$ (v/v) methanol was added to $4 \mathrm{ml}$ of extract, then heated to just warm. Magnesium fillings were added followed by a few drops of $\mathrm{HCl}$ acid. A pink colour was observed which indicated the presence of flavonoids. Tannins: Distilled water was used to dilute extract and on adding a few drops of $\mathrm{FeCl}_{3}$, green colour was observed. Glycosides: Plant was extracted with methanol, Fehling's reagent was added to the extract and boiled for a few minutes. A brick red colouration indicated the presence of glycosides. Carbohydrate: Plant extract was heated with Fehling solution and a red precipitate was observed. Protein: A few drops of Millon's reagent was added to $5 \mathrm{ml}$ of extract. The mixture was gradually boiled. A reddish colour was observed. Phenols: A few drops of neutral $\mathrm{FeCl}_{3}$ was added to $0.5 \mathrm{ml}$ extract and a violet coloured complex was observed.

\subsection{Synthesis of zinc oxide nanoparticles}

In this study, $\mathrm{ZnO}$ nanoparticles were prepared by two different methods; the green method and the chemical method. In green method, $13.38 \mathrm{~g}$ of zinc nitrate was added dropwise to $50 \mathrm{ml}$ of the plant extract for about an hour while stirring at $70^{\circ} \mathrm{C}$ using a magnetic stirrer heater. The mixture was left for more than $1 \mathrm{~h}$ for the complete reduction of $\mathrm{Zn}(\mathrm{OH})_{2}$. Then the reaction mixture was subjected to centrifugation and numerous washing using distilled deionized water. The dispersion formed was centrifuged at $5000 \mathrm{rpm}$ for $30 \mathrm{~min}$ at $4^{\circ} \mathrm{C}$ in order to remove unbound organics and re-dispersed in distilled deionized water. The nanoparticles were dried in a vacuum overnight and kept at $60^{\circ} \mathrm{C}$. The nanoparticles were mashed in a mortar-pestle so as to get a fine powder for further characterization. In the chemical method, $13.38 \mathrm{~g}$ of aqueous solution of zinc nitrate $\left(\mathrm{Zn}\left(\mathrm{NO}_{3}\right)_{2} \cdot 4 \mathrm{H}_{2} \mathrm{O}\right)$ and $3.6 \mathrm{~g}$ aqueous solution of sodium hydroxide $(\mathrm{NaOH})$ were prepared in $50 \mathrm{ml}$ distilled water solution. The beaker containing $\mathrm{NaOH}$ solution was heated at a temperature of about $70^{\circ} \mathrm{C}$ under constant stirring using a magnetic stirrer heater for a period of $1 \mathrm{~h}$. The $\mathrm{Zn}\left(\mathrm{NO}_{3}\right)_{2}$ solution was added dropwise (slowly for $60 \mathrm{~min}$ ) to the heated solution of $\mathrm{NaOH}$ under high speed stirring using a magnetic stirrer to obtain a homogeneous solution. The beaker was sealed under vacuum in this condition for $2 \mathrm{~h}$. The precipitated $\mathrm{ZnO}$ nanoparticles were cleaned with deionized water and ethanol for about 6-10 times in order to remove the byproducts, which were bound with the nanoparticles and then filtered using filter paper. The white bulky residue obtained was air dried at about $60^{\circ} \mathrm{C}$ for $6 \mathrm{~h}$. During drying, $\mathrm{Zn}(\mathrm{OH})_{2}$ is completely converted into $\mathrm{ZnO}$ nanoparticles.

\subsection{Characterization techniques}

Scanning electron microscopy (SEM) analysis of the green and chemically synthesized zinc oxide nanoparticles was done using a Hitachi S4160 scanning electron microscope (SEM) in order to determine the morphology of the reaction products that were formed. Fourier transform infrared (FTIR) spectrum was obtained using Shimadzu Fourier Transform Infra-Red Spectrometer (FTIR) 8300 series located at Redeemers University, Nigeria in order to confirm the functional groups present in the zinc oxide nanoparticles. The spectral range of the FTIR spectrometers was 4000$400 \mathrm{~cm}^{-1}$. Powder X-ray diffraction was performed using an X-ray Diffractometer, Shimadzu, XRD-6000 with CuKa radiation $\lambda=1.5405 \AA$ over a wide range of Bragg angles $\left(20^{\circ} \leq 2 \theta \leq 80^{\circ}\right)$. Optical properties analysis was done using an UV-Vis spectrophotometer and the elemental composition was obtained using energy dispersive X-ray spectroscopy (EDX).

\subsection{Antimicrobial inhibition tests of the zinc oxide nanoparticles}

Among metal oxide powders, $\mathrm{ZnO}$ nanoparticles demonstrate very significant growth inhibition of a broad spectrum of bacteria. In this study, the antibacterial activity of the synthesized $\mathrm{ZnO}$ nanoparticles was evaluated against three test organisms by agar well diffusion method [26]. The test organisms used include: P. aeruginosa, S. typhi and S. dysenteriae. A sterile cork-borer four wells of $6 \mathrm{~mm}$ diameter made on a nutrient agar plate was used. The plates containing the microbes and $\mathrm{ZnO}$ nanoparticles were incubated at $37^{\circ} \mathrm{C}$ and the antimicrobial activity for the green and chemically synthesized $\mathrm{ZnO}$ nanoparticles was compared. The plates were examined for evidence of zones of inhibition, which appear as a clear area 
around the wells [27] and discs. The diameter of such zones was measured using a metre ruler and the mean value for each organism was recorded and expressed in millimetre. The test isolates were collected from the Department of Microbiology, Obafemi Awolowo University, Ile-Ife, Nigeria. One gram of zinc oxide was mixed with $5 \mathrm{ml}$ of $100 \%$ methanol to form a stock solution. About $5 \mathrm{ml}$ nutrient broth was prepared in test tubes and sterilized. A single isolated colony of bacteria was inoculated in the prepared nutrient broth and incubated at $37^{\circ} \mathrm{C}$ for $18-24 \mathrm{~h}$. After incubation, the tubes were centrifuged for $30 \mathrm{~min}$ and the supernatant was decanted, leaving the cell pellets. The cell pellets were washed with normal saline three times to wash-off the broth. A few drops of normal saline was added to the cell pellets and shaken to form the test organisms' suspension in the tubes and then adjusted to $0.5 \mathrm{McF}$ arland standards. About $20 \mathrm{ml}$ of Muller-Hinton Agar was prepared in McCartney bottles, sterilized and thereafter poured into petri-plates and allowed to set. Sterile swab sticks were dipped into the standardized tubes containing the test organisms and swabbed across the set plates. Flamed cork-borer was used to make three wells on the swabbed plates and $1 \mathrm{ml}$ from stock solution of zinc oxide concentration were dispensed into two wells while sterile distilled water was dispensed into the third well and incubated at $37^{\circ} \mathrm{C}$ for $18-24 \mathrm{~h}$. After incubation, the swabbed plates were measured to check their zones of inhibition. The average width $(W)$ of the zone of inhibition on either side of the well was calculated as follows: $W=(T-D)$, where $T$ is total diameter of the well and clear zone (in $\mathrm{cm}$ ) and $D$ is diameter of the well (in $\mathrm{cm}$ ). A well with distilled water was used as negative control while a well with undiluted concentration of each disinfectant was used as positive control.

\section{Results and discussion}

\subsection{Phytochemical screening}

The phytochemical characters of A. spinosus were investigated and summarized in table 1 . The result shows the presence of phenols, terpenoids, alkaloids, tannins, saponins and glycosides. The phytochemicals that have been demonstrated to have antimicrobial activity are flavonoids, terpenoids and tannins [28]. Tannins can form irreversible complexes with proline rich proteins [23] therefore resulting in the inhibition of microbe cell protein. Terpenoids have been demonstrated to be active against bacteria [29], which has enabled food scientists to use terpenoids present in essential oils of plants to control Listeria monocytogenes. Flavonoids are known to be produced in plants in response to microbial infections [30].

\subsection{Optical measurements}

The bio reduction of the synthesized $\mathrm{ZnO}$ was monitored with an UV-Visible spectrophotometer. Aliquot sample of the nanoparticles was taken at various time intervals. The evidence of reaction completion in bio-nanozinc formation was indicated by a colour change observed from light yellow to near brown with a corresponding single peak in the absorbance spectra (figure 1B) which took place within $60 \mathrm{~min}$. It also shows the absorbance peak between 646 and $694 \mathrm{~nm}$ with the highest peak at $678 \mathrm{~nm}$.

\subsection{FTIR studies}

FTIR spectroscopy measures the absorption of infrared radiations by a sample and the results of such analysis are shown, using a wavelength. Figure 2A shows the FTIR spectrum of $\mathrm{ZnO}$ nanoparticles prepared from aqueous $S$. amaranth leaf extract by green synthesis. The fundamental mode of vibration at $3266.10 \mathrm{~cm}^{-1}$ corresponds to the stretching vibration of intermolecular hydrogen bond $(\mathrm{O}-\mathrm{H})$ existing between the adsorbed water molecule and oxygen of zinc oxide. The peak at $1645.13 \mathrm{~cm}^{-1}$ corresponds to the $\mathrm{N}-\mathrm{H}$ stretching vibration, while the peak at $2091.47 \mathrm{~cm}^{-1}$ corresponds to $\mathrm{C}-\mathrm{C}$ stretching vibration of polyol, carboxylic acid, ether and ester and this implies bonding with plant extract phytochemicals. The peak at $1154.01 \mathrm{~cm}^{-1}$ corresponds to $\mathrm{C}-\mathrm{N}$ symmetric stretching vibration. The stretching vibration of $\mathrm{C}-$ $\mathrm{O}$ is at $1027 \mathrm{~cm}^{-1}$. The peaks at 558.71 and 700.18 $\mathrm{cm}^{-1}$ indicate the stretching vibrations of $\mathrm{ZnO}$ nanoparticles which is consistent with that reported before by Kumar et al [30]. Figure 2B shows the FTIR spectrum of $\mathrm{ZnO}$ nanoparticles prepared by a chemical method. The peaks at 459 and $424 \mathrm{~cm}^{-1}$ are related to the stretching vibrations of $\mathrm{ZnO}$ nanoparticles bonds [7]. The peak at $3419 \mathrm{~cm}^{-1}$ indicates the presence of $-\mathrm{OH}$ residue; probably due to atmospheric moisture [24]. The stretching vibration of $\mathrm{C}-\mathrm{O}$ is at $1045 \mathrm{~cm}^{-1}$. The peak at $2926 \mathrm{~cm}^{-1}$ is due to $\mathrm{C}-\mathrm{H}$ stretching vibration of alkane groups. The peaks observed at 1633 and $1384 \mathrm{~cm}^{-1}$ are due to the asymmetrical and symmetrical stretching of the zinc carboxylate respectively. The carboxylate probably comes from reactive carbon containing plasma species during the synthesis.

\subsection{Structural studies (X ray diffractometer)}

Figure $3 \mathrm{~A}$ and $\mathrm{B}$ shows the X-ray diffraction (XRD) pattern of $\mathrm{ZnO}$ nanoparticles synthesized by chemical and green method respectively. The XRD pattern in figure $3 \mathrm{~A}$ revealed the orientation and crystalline nature of zinc oxide nanoparticles. The sharp diffraction peaks apparent in the figure indicate good crystallinity of the $\mathrm{ZnO}$ nanoparticles. The diffraction peaks at $2 \theta=31.77,34.4,36.2,47.5,56.6,62.8$ and 67.9 that belongs to the (100), (002), (101) and (102), (110), (103), (200), (112) diffraction planes, respectively are ascribed to the hexagonal structure of $\mathrm{ZnO}$ nanoparticles which are in good agreement with that of the typical wurtzite structure $\mathrm{ZnO}$ nanoparticles obtained from the International Center of Diffraction Data card (JCPDS 36-1451). The average crystallite size of 

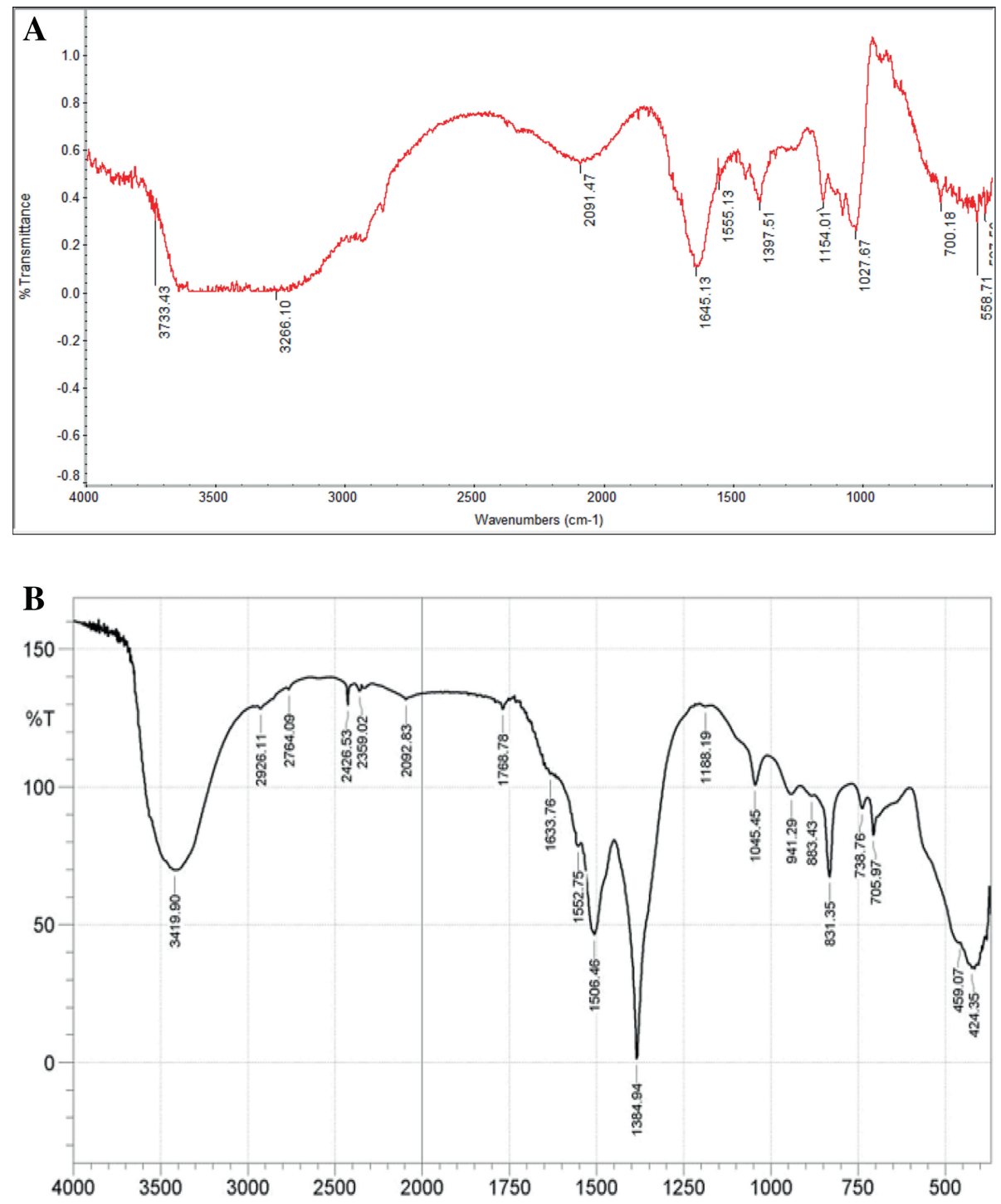

Figure 2. FTIR spectrum of $\mathrm{ZnO}$ nanoparticles using (A) green method and (B) chemical method.

the zinc oxide nanoparticles was calculated and found to be $21.1 \mathrm{~nm}$ using Debye-Scherrer equation $[31,32]$ where the crystallite size of zinc oxide nanoparticles, wavelength of $\mathrm{X}$-ray source $0.1541 \mathrm{~nm}$ used in XRD, full width at half maximum of the diffraction peak, Scherrer constant with value from 0.9 to 1 and Bragg angle are employed.

Figure 3B shows the XRD pattern of the green synthesized $\mathrm{ZnO}$ nanoparticles. The peaks corresponding to the diffraction planes (100), (002), (101), (102) and (103) were obtained. A comparison of observed XRD pattern with the standard JCPDS card data indicates that, all the peaks are matched with standard JCPDS card no. 36-1451, although, the peaks present were not prominent and amorphous structure was observed. The amorphous nature might be due to complex formation with phytochemicals in the plant extract. Further confirmation for the formation of $\mathrm{ZnO}$ using the green method was done using $\mathrm{EDX}$ and formation of $\mathrm{ZnO}$ nanoparticles was confirmed.

\subsection{Morphological studies (SEM)}

Figure 4A shows the typical SEM image of the $\mathrm{ZnO}$ nanoparticles. This image demonstrates that a bulk quantity of flower-like bunches exist. Each bunch consists of closely packed nanometre scale rods and forms radiating structures. The morphology clearly demonstrates the formation of $\mathrm{ZnO}$ nanoparticles. The morphology of $\mathrm{ZnO}$ nanoparticles prepared by green method is shown in figure 4B. It can be seen that nanoparticles are in the form of agglomerates and exist as particles that are much larger than $200 \mathrm{~nm}$ and some are even micron sized. 

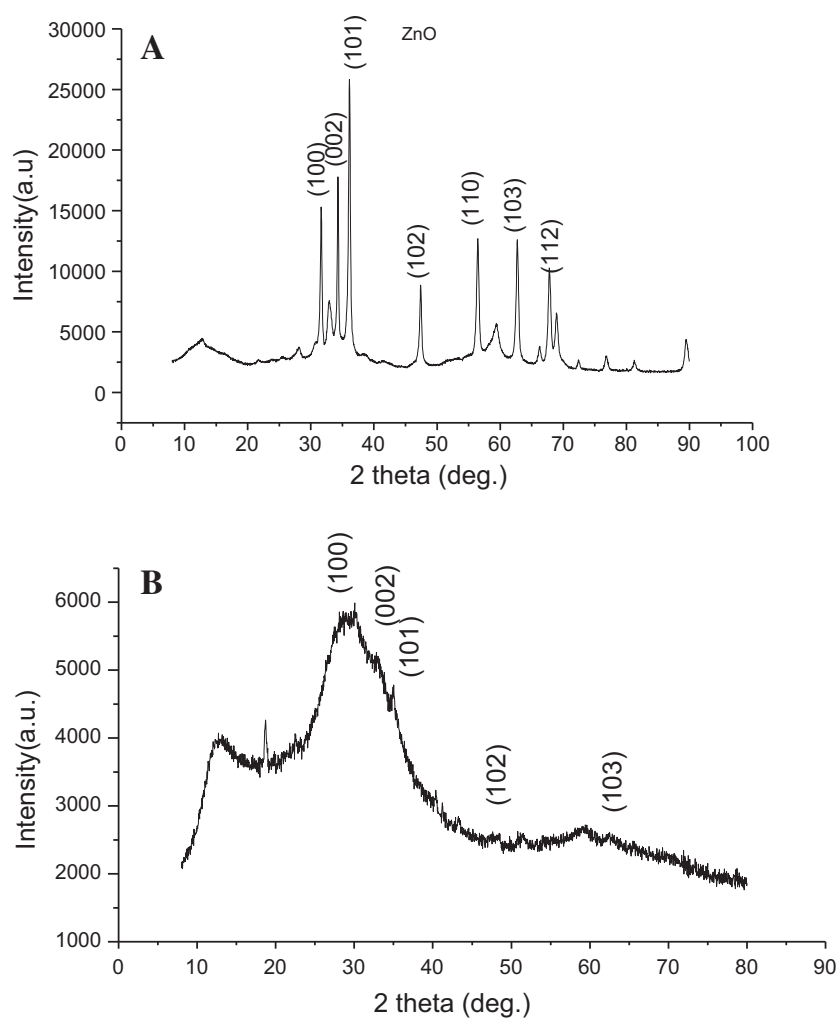

Figure 3. XRD spectra of $\mathrm{ZnO}$ nanoparticles using (A) chemical method and (B) green method.

\subsection{Elemental composition (EDX)}

Figure 4C shows the EDX spectrum of the green synthesized $\mathrm{ZnO}$ nanoparticles. The EDX analysis confirmed formation of $\mathrm{ZnO}$ nanoparticles. The presence of carbon originated from the plant extracts and from the carbon that was used during carbon coating of SEM analysis.

\subsection{Antimicrobial inhibition test}

The dimension of nanoparticles may facilitate easy entry into the microbial cell membrane enabling inhibition mechanisms to occur inside the cell. In this work, the antimicrobial activities of $\mathrm{ZnO}$ nanoparticles tested against $P$. aeruginosa, $S$. typhi and $S$. dysenteriae were quantitatively evaluated in culture media. The values of zone of inhibition obtained are presented in table 2, while antimicrobial activities for green and chemical methods are shown in figure 5. From the study, it was observed that the growth inhibition ( $\mathrm{mm}$ ) was solely higher in green synthesized $\mathrm{ZnO}$ than the chemically synthesized $\mathrm{ZnO}$ nanoparticles. The presence of inhibition zone clearly indicates that the mechanism of the biocidal action of $\mathrm{ZnO}$ nanoparticles involves disruption of the membrane with a high rate of generation of surface oxygen species and finally leads to the death of pathogens. The antibacterial mechanism of $\mathrm{ZnO}$ nanoparticles involves the direct interaction between $\mathrm{ZnO}$ nanoparticles and cell surfaces. This affects cell membrane permeability; then these nanoparticles enter and induce oxidative stress in bacterial cells. Inhibition of cell growth occurs, which can eventually lead to cell death. The demonstrated antibacterial activity of $\mathrm{ZnO}$ nanoparticles
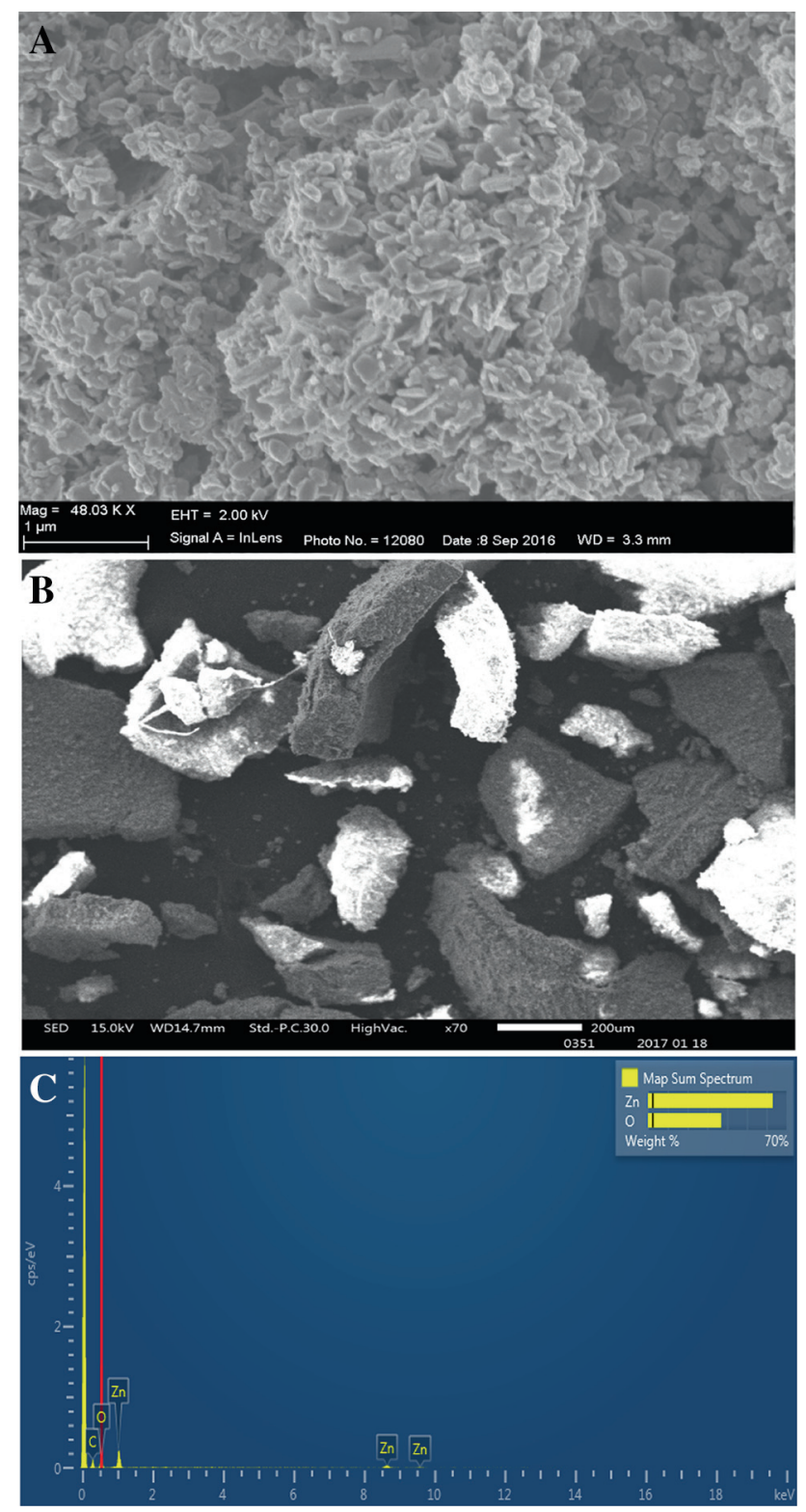

Figure 4. SEM image of $\mathrm{ZnO}$ nanoparticles by (A) chemical method, (B) green method and (C) EDX spectrum of $\mathrm{ZnO}$ nanoparticles.

Table 2. Antimicrobial activity of $\mathrm{ZnO}$ nanoparticles synthesized by green and chemical method.

\begin{tabular}{lcc}
\hline Organism & $\begin{array}{l}\text { Zone of inhibition } \\
\text { (green) }\end{array}$ & $\begin{array}{l}\text { Zone of inhibition } \\
\text { (chemical) }\end{array}$ \\
\hline S. typhi & No zone & Faint clear zone \\
S. dysenteriae & Trace & No zone \\
P. aeruginosa & $16 \mathrm{~mm}$ & No zone \\
\hline
\end{tabular}


Chemically Synthesized ZnO

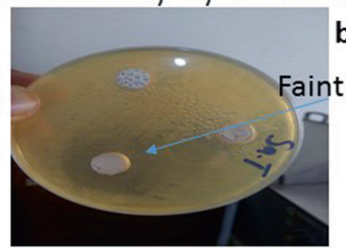

bacteriostatic

Faint zone : $2 \mathrm{~mm}$

Salmonella typhi

Green Synthesized ZnO

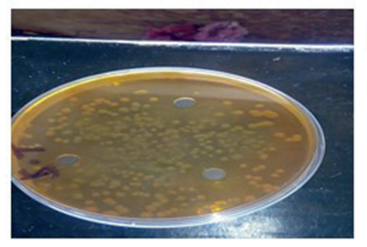

bacteriocidal
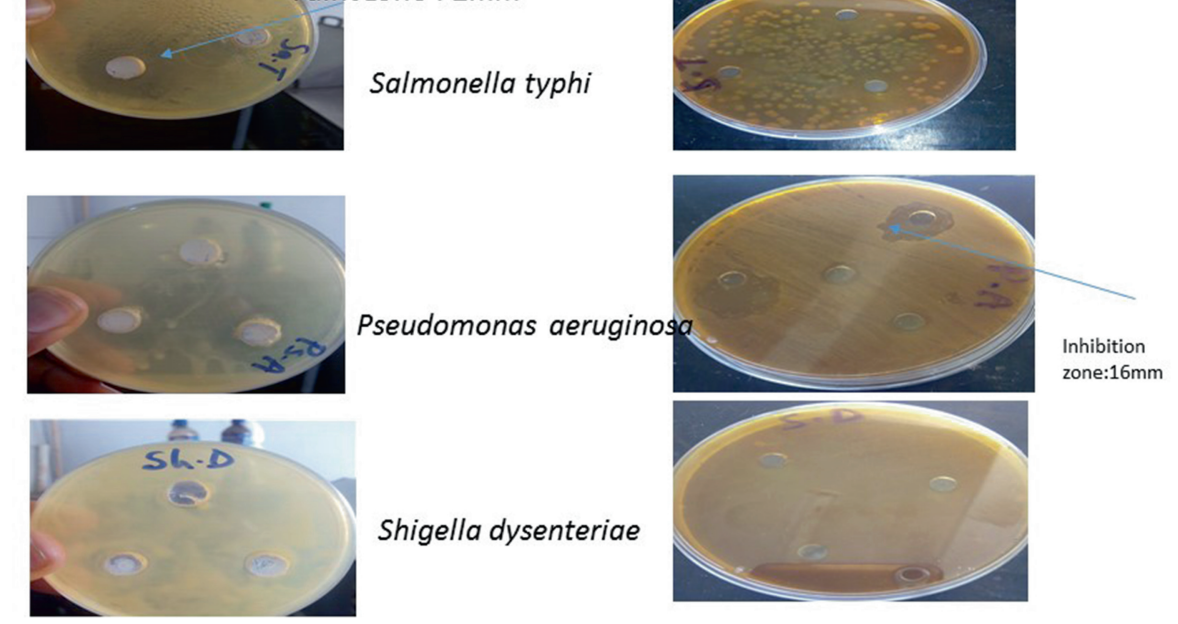

Shigella dysenteriae

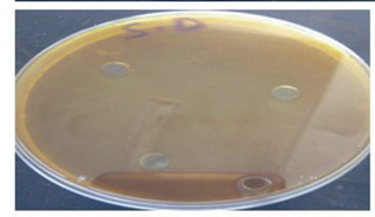

Figure 5. Antibacterial activity of green and chemically synthesized zinc oxide nanoparticles against P. aeruginosa, S. dysenteriae and S. typhi.

Green synthesis:

\section{$\mathrm{Zn}(\mathrm{NO})_{3}+$ Plant Extract}
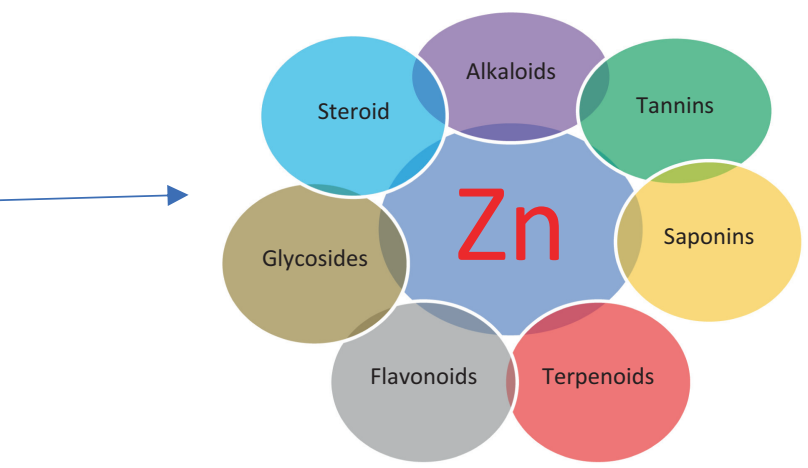

recommends its possible application in the food preservation field. It can be applied as a potent sanitizing agent for disinfecting and sterilizing food industry equipment and containers against the attack and contamination of foodborne pathogenic bacteria. Contribution from plant extracts to the enhancement of antimicrobial properties of green $\mathrm{ZnO}$ are related to the ability to synthesize several phytochemicals such as tannins, alkaloids, cardiac glycosides, terpenoids, steroids, flavonoids and saponins complexed with the zero valent metal by secondary metabolism.

The equations of the reaction are given below:

Chemical synthesis:

$$
\begin{aligned}
& \mathrm{Zn}\left(\mathrm{NO}_{3}\right)_{2}+2 \mathrm{NaOH} \rightleftharpoons \mathrm{Zn}(\mathrm{OH})_{2}+2 \mathrm{NaNO}_{3} \\
& \mathrm{Zn}(\mathrm{OH})_{2} \rightleftharpoons \mathrm{ZnO}+\mathrm{H}_{2} \mathrm{O}
\end{aligned}
$$

\section{Conclusions}

This work presents evaluation of microbial inhibition properties of green and chemically synthesized $\mathrm{ZnO}$ nanoparticles. The results showed that the green synthesized $\mathrm{Zn}$ is zerovalent, therefore forming complexes with the phytochemicals for better antimicrobial properties than the latter. Furthermore, a complexation reaction with plant extract phytochemicals, is confirmed by XRD diffractogram, FTIR and EDX spectra. The reaction equations are given above. It can be inferred that the chemically synthesized $\mathrm{ZnO}$ nanoparticles are bacteriostatic and not bactericidal. Though chemical and green methods are trendier for nanoparticles synthesis, biogenic green fabrication is a better choice due to ecofriendliness, good microbial inhibition properties and can 
be an effective alternative for the large scale synthesis of nanoparticles and possible application in the food preservation field. Phytochemicals contribute to merits of green and eco-friendly nanoparticle properties.

\section{References}

[1] Akinsiku A A, Dare E O, Ajanaku K O, Adekoya J A, Alayande S O and Adeyemi A O 2016 J. Bionanosci. 10171

[2] Sosa I O, Noguez C and Barrera R G 2003 J. Phys. Chem. B 1076269

[3] Sun Y G, Mayers B, Herricks T and Xia Y N 2003 Nano Lett. 3 955

[4] Duran N, Marcato P D, Alves O L and Souza G 2005 J. Nanotechnol. 31

[5] Ingle A, Gade A, Pierrat S, Sonnichsen C and Rai M 2008 Curr. Nanotechnol. 4141

[6] Taylor P L, Ussher A L and Burrell R E 2005 Biomaterials 26 7221

[7] Santhoshkumar J, Venkat Kumar S and Rajeshkumar S 2017 Res. Eff. Technol. 3459

[8] Baglioni P, Dei L, Fratoni L, Nostro L P and Moroni M 2003 Patent 8827

[9] Fei B, Deng Z, Xin J H, Zhang Y and Pang G 2006 Nanotechnology 171927

[10] Vigneshwaran N, Kumar S, Kathe A A, Varadarajan P V and Prasad V 2006 Nanotechnology 175087

[11] Wang R H, Xin J H, Tao X M and Daoud W A 2004 Chem. Phys. Lett. 398250

[12] Arabi F, Imandar M, Negahdary M, Imandar M, Noughabi M T, Akbari-Dastjerdi H et al 2012 Schl. Res. Lib. Ann. Biol. Res. 3 3679

[13] Wu Y L, Tok A I Y, Boey F Y C, Zeng X T and Zhang X H 2007 Appl. Surf. Sci. 2535473
[14] Chen S, Kumar R V, Gedanken A and Zaban A 2001 Isr J. Chem. $\mathbf{4 1} 51$

[15] Ghaffarian H R, Saiedi M and Sayyadnejad M A 2011 Iran J. Chem. Eng. 301

[16] Kelly P, Conxitasolans G V and Margarita S 2012 Chem. Lett. 411032

[17] Neetu S, Davinder K, Mehra R M and Avinashi K 2012 Open Renew. Energy J. 515

[18] Sharma D, Kanchi S and Bisetty K 2015 Arab. J. Chem. https:// doi.org/10.1016/j.arabjc.2015.11.002

[19] Sabir S, Arshad M and Chaudhari S K 2014 Sci. World J. 2014 925494

[20] Bhagyashree D, Varsha C and Bhawana P 2017 Indian J. Sci. Res. 1241

[21] Maiyo Z C, Ngure R M, Matasyoh J C and Chepkorir R 2010 Afr. J. Biotechnol. 93178

[22] Nascimento G G, Locatelli J and Freitas P C 2000 Braz. J. Microbiol. 31247

[23] Akinpelu D A and Onakoya T M 2006 Afr. J. Trad. 3112

[24] Becheri A, Durr M, Nostro P L and Baglioni P $2008 \mathrm{~J}$. Nanopart. Res. 10679

[25] Das S 2012 Genet. Resour. Crop Evol. 59289

[26] Nanda A and Saravanan M 2009 Nanomed. Nanotechnol. Biol. Med. 5452

[27] Cheesbrough M 2000 District laboratory practice in tropical countries (Cambridge, UK: The Press Syndicate of the University of Cambridge) p 157

[28] Stern J L, Hagerman A E, Steinberg P D and Mason P K 1996 J. Chem. Ecol. 221887

[29] Tassou C C, Drosinos E H and Nychas G J E 1995 J. Appl. Bacteriol. 78593

[30] Dixon R A, Dey P M and Lamb C J 1983 Mol. Biol. Adv. Enzyme $\mathbf{5 5} 1$

[31] Kumar H and Rani R 2013 Int. Lett. Chem., Phys. Astron. 14 26

[32] Cullity B D 1978 The elements of X-ray diffraction (Boston, USA: Addison-Wesley) p 102 